\title{
Article
}

\section{Laser-Induced Graphene Heater Pad for De-Icing}

\author{
Jun-Uk Lee ${ }^{1,+}$, Chan-Woo Lee ${ }^{1,+}\left(\mathbb{C}\right.$, Su-Chan Cho ${ }^{1,+}$ and Bo-Sung Shin ${ }^{2, *}$ (i) \\ 1 Department of Cogno-Mechatronics Engineering, Pusan National University, Pusan 46241, Korea; \\ lju3534@naver.com (J.-U.L.); cwleeho2@naver.com (C.-W.L.); cho_brian@naver.com (S.-C.C.) \\ 2 Department of Optics and Mechatronics Engineering, Pusan National University, Pusan 46241, Korea \\ * Correspondence: shinbs7123@gmail.com; Tel.: +82-51-510-2787 \\ + These authors contributed equally to this work.
}

\section{check for}

updates

Citation: Lee, J.-U.; Lee, C.-W.; Cho, S.-C.; Shin, B.-S. Laser-Induced Graphene Heater Pad for De-Icing. Nanomaterials 2021, 11, 3093.

https://doi.org/10.3390/nano11113093

Academic Editor: Ana M. Benito

Received: 15 October 2021

Accepted: 5 November 2021

Published: 16 November 2021

Publisher's Note: MDPI stays neutral with regard to jurisdictional claims in published maps and institutional affiliations.

Copyright: (c) 2021 by the authors. Licensee MDPI, Basel, Switzerland. This article is an open access article distributed under the terms and conditions of the Creative Commons Attribution (CC BY) license (https:/ / creativecommons.org/licenses/by/ $4.0 /)$.

\begin{abstract}
The replacement of electro-thermal material in heaters with lighter and easy-to-process materials has been extensively studied. In this study, we demonstrate that laser-induced graphene (LIG) patterns could be a good candidate for the electro-thermal pad. We fabricated LIG heaters with various thermal patterns on the commercial polyimide films according to laser scanning speed using an ultraviolet pulsed laser. We adopted laser direct writing (LDW) to irradiate on the substrates with computer-aided 2D CAD circuit data under ambient conditions. Our highly conductive and flexible heater was investigated by scanning electron microscopy, transmission electron microscopy, Raman spectroscopy, thermogravimetric analysis, $\mathrm{X}$-ray photoelectron spectroscopy, $\mathrm{X}$-ray diffraction, and Brunauer-Emmett-Teller. The influence of laser scanning speed was evaluated for electrical properties, thermal performance, and durability. Our LIG heater showed promising characteristics such as high porosity, light weight, and small thickness. Furthermore, they demonstrated a rapid response time, reaching equilibrium in less than $3 \mathrm{~s}$, and achieved temperatures up to $190^{\circ} \mathrm{C}$ using relatively low DC voltages of approximately $10 \mathrm{~V}$. Our LIG heater can be utilized for human wearable thermal pads and ice protection for industrial applications.
\end{abstract}

Keywords: flexible; laser-induced graphene; polyimide; heater

\section{Introduction}

Flexible graphene-based electronics are rapidly gaining interest because graphene, a unique two-dimensional (2D) nanomaterial, has great potential in electronics owing to its high electrical conductivity, excellent mechanical flexibility, and optical and thermal properties [1-4]. The electrothermal effect of graphene-based materials has received much attention because it is expected that they will substitute heavy metal heater products in a variety of fields, especially in the aeronautics and automotive industries, for de-icing and icing protection [5-7]. However, the feasibility of graphene-based heaters has been impeded by challenges such as difficulty in matching the high efficiency of metal heaters and the complex fabrication processes of graphene, such as chemical vapor deposition (CVD) and wet-chemical approaches [8-11]. Graphene-based heaters generally include the deposition of graphene oxide (GO) for its reduction and the multiple transfer of graphene [12-17]. Although these graphene-based composites have sufficient properties for manufacturing heaters, these processes are limited to resolving the challenges of economically viable mass production.

In 2014, a promising alternative to printed graphene patterns, called laser-induced graphene (LIG), was presented by Tour et al. [18]. They irradiated an abundant carbon precursor substrate to fabricate LIG using inexpensive and accessible $10.6 \mu \mathrm{m} \mathrm{CO} 2$ lasers, which are commonly used for cutting and etching in industry. LIG is a one-step, lithography-free process upon which a laser converts $s p^{3}$-hybridized carbon found in polymeric substrates into $s p^{2}$-hybridized carbon, which is the carbon allotrope found in graphene. LIG is a versatile technique that has been used to produce 3D graphene that is 
superhydrophobic or hydrophilic, doped with metal oxide nanocrystals, functionalized with polymers, or developed into vertically aligned graphene fibers [19-24]. The utility of LIG has been demonstrated in numerous applications, including supercapacitors, non-biofouling surfaces, transparent electrodes, sensors, and triboelectric nanogenerators [25-29]. LIG has opened up a multitude of possibilities for the mass production of a wide range of novel, eco-friendly 3D graphene-based applications. The simplified architecture and facile fabrication of $3 \mathrm{D}$ graphene allows for the full integration with the emerging field of one-step printed electronics, because this facile LIG manufacturing protocol eliminates the need for ink preparation, ink printing, and post-print annealing processes associated with solution-phase printed circuits [30-34]. While promising graphene-printed flexible electronics have been demonstrated at a lab scale, there is limited research on LIG-based applications such as heaters and gas sensors using the electrothermal effect based on localized Joule heating [35-38].

Considering the immense potential of LIG and the limited research on its thermoelectric applications, we studied herein the electrothermal performance of LIG patterns fabricated by an ultraviolet (UV) pulsed laser instead of a continuous wavelength (CW) infrared (IR) laser with high laser power. We adopted laser direct writing (LDW) to irradiate the polyimide (PI) films with computational circuit patterns with $2 \mathrm{D}$ CAD data under ambient conditions. Conductive LIG patterns can be easily fabricated using LDW on demand for customized patterns. To ensure the advantages of LIG patterns, the prepared LIG heaters were evaluated in terms of their electrical properties, electrothermal performance, and mechanical durability. The LIG heater demonstrated a rapid response time, reaching equilibrium within $3 \mathrm{~s}$ and achieving temperatures up to $190{ }^{\circ} \mathrm{C}$ using relatively low DC voltages of approximately $10 \mathrm{~V}$. Their outstanding characteristics were confirmed by applying them to human wearable thermal pads and ice protection for industrial applications.

\section{Materials and Methods}

\subsection{Laser Delivery System}

A commercial $355 \mathrm{~nm}$ pulsed laser system (AONano 355-5-30-V from Advanced Optowave, Ronkonkoma, NA, USA) was used as the laser source for fabricating the LIG. Our Nd : $\mathrm{YVO}_{4}$ laser with a maximum average power of $5 \mathrm{~W}$ at $\lambda=355 \mathrm{~nm}$, pulse length $\tau=15 \mathrm{~ns}$, and repetition rate $f=30 \mathrm{kHz}$ was used to irradiate the samples in a standard atmospheric environment $\left(25^{\circ} \mathrm{C}\right.$ and normal pressure), as described in Table S1. LDW was adopted for the preparation of LIG patterns during laser induction under ambient conditions at room temperature. Laser beam delivery was performed by moving the mirrors of the galvano scanner (HurrySCAN III 14 from SCANLAB, Pucheim, Germany) and the F- $\theta$ lens of focal length $\mathrm{f}=105.9 \mathrm{~mm}$ (S4LFT4100/075 Telecentric Scan Lens from Sill Optics, Wendelstein, Germany). In general, four key parameters are expected to affect laser-induced carbonization: laser power, scanning speed, hatch distance, and laser mode of scanning. In our best conditions, we fixed the laser parameters in the configuration where laser power $=1.3 \mathrm{~W}$, hatch distance $=0.1 \mathrm{~mm}$, and laser scan mode was unidirectional.

\subsection{Fabrication of Prepared LIG Heater by UV Pulsed Laser}

Table S2 describes our laser beam conditions for the LIG patterns. PI film (Kapton ${ }^{\circledR}$ $\mathrm{HN}$ ) with $125 \mu \mathrm{m}$ thickness from Dupont ${ }^{\mathrm{TM}}$ (Wilmington, DE, USA) was used as received. Kapton has a significant optical transmittance in the $10.6 \mu \mathrm{m}$ region, which results in a rather deep penetration in the polymer substrate [24]. This limits the minimum thickness of the Kapton substrate, either by the complete penetration of the polymer or by the buckling of the film owing to the photothermal process, leading to non-flat devices that could be an obstacle for mechanical durability [39]. However, because of the presence of chromophores (conjugated double bonds and multi-aromatic rings) in the Kapton films, there is a strong complicated absorption in the ultraviolet region [40]. Although the absorption rate varies depending on the fluence, it has an absorption rate of over $85 \%$ from a very low fluence 
of $10 \mathrm{~mJ} / \mathrm{cm}^{2}$ at a $355 \mathrm{~nm}$ wavelength [41]. This interaction between PI and a UV-pulsed laser allows for both thinner and narrower devices. Figure S1 shows that various types of laser-patterned LIG samples were successfully produced using our defocused laser beam conditions.

The fabrication process is illustrated schematically in Figure 1. As shown in Figure 1a, the laser beam was scanned with the cross-hatching process to form grooved LIG patterns. The hatch distance was fixed at $0.1 \mathrm{~mm}$. Both the horizontal and vertical scan modes gave high roughness to the surface.

(a)

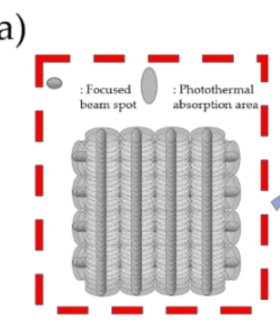

(e)

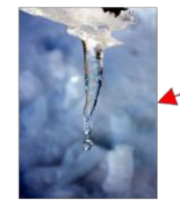

De-icing

(f)

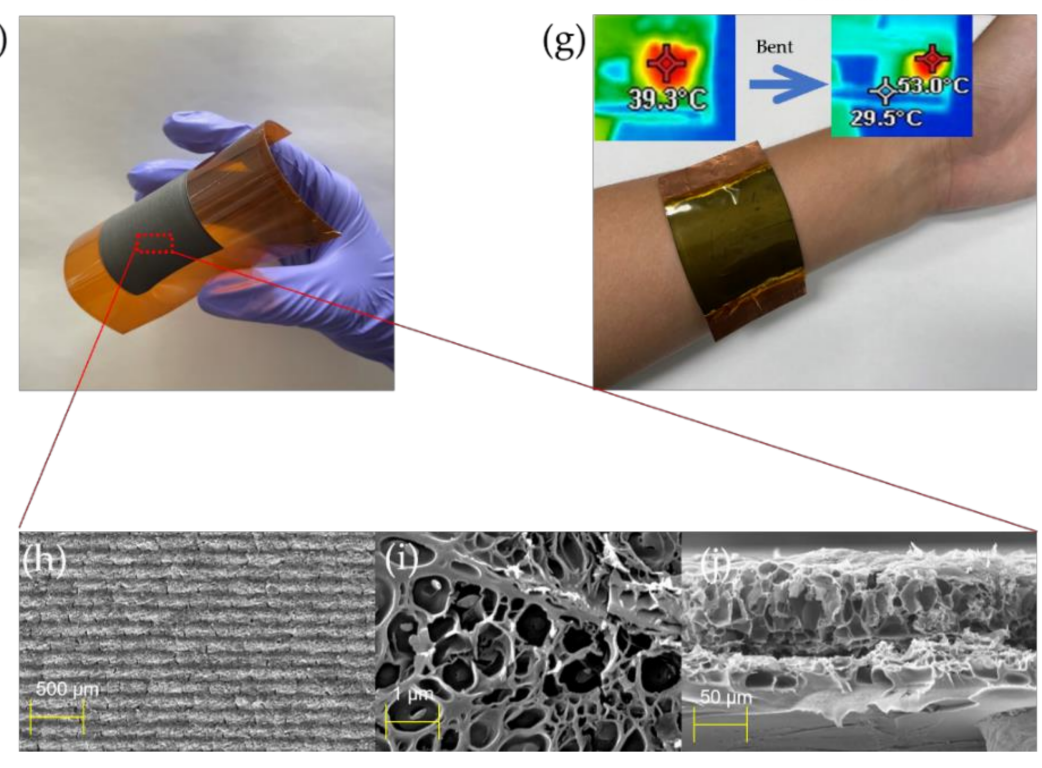

(b)

355-nm nanosecond-pulsed UV laser
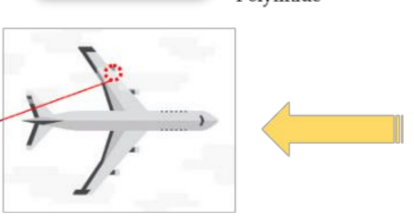

Aluminum foil

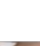

(c)

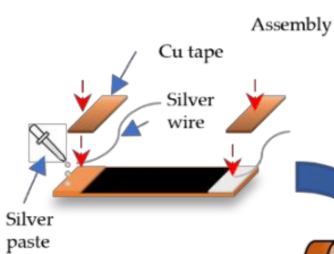

(d)
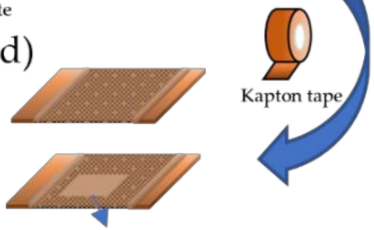

8

\section{.}


As shown in Figure 1e, a heater pad could be used to defrost the aircraft's wings by joule heating. Figure $1 \mathrm{f}, \mathrm{g}$ show actual photographs of the LIG patterns and wearable heater pad, respectively. They show good flexibility for human motion. As shown in Figure 1h,i, our LIG pattern had a unique structure. When observed from the top view, the shape of the pattern was maintained, but pores were formed inside. The intersection in Figure $1 j$ also shows that the structure of the LIG pattern contains many pores. This unusual pattern has the effect of accumulating generated heat in the pores.

\subsection{Characterization}

Optical photographs of the LIG patterns were taken with an optical microscope (BX60M system OLYMPUS, Shinjuku, Japan). Field emission scanning electron microscopy (FE-SEM) of the LIG was conducted on a field emission scanning electron microscope (TESCAN MIRA 3 LMH In-Beam Detector, Brno, Czech Republic). Transmission electron microscopy (TEM) images were obtained using a JEM-2100F microscope (JEOL, Akishima, Tokyo). Raman spectra were measured using a Raman spectrometer (NRS-5100 JASCO International Co., Ltd., Tokyo, Japan) with a $532 \mathrm{~nm}$ excitation line. Fourier transform infrared spectroscopy (FTIR) spectra were obtained using an FTIR-4100 type A instrument with an ATR-PRO 450-S accessory (JASCO International Co., Ltd., Tokyo, Japan). To analyze the composition and chemical bond states of the LIG patterns, X-ray photoelectron spectroscopy (XPS) spectra were analyzed using a K-Alpha ${ }^{\mathrm{TM}}$ X-ray Photoelectron Spectrometer System (Thermo Scientific, Waltham, MA, USA). The composition and crystal structure of the prepared LIG samples were determined by X-ray diffraction (XRD) using an X'Pert-MPD System (PHILIPS, Amsterdam, The Netherlands) with $\mathrm{Cu}$ K- $\alpha$ radiation $(\lambda=1.54 \AA)$. The instantaneous electrothermal performance was recorded using an LCR meter 4100 (Wanye Kerr Electronics, Woburn, MA, USA) and a Keithley 2450 source meter (Keithley Tektronix, Beaverton, OR, USA). The zeta potentials were analyzed using a Litesizer 500 (Anton Paar, Graz, Austria). The surface area and pore size were recorded using an Autosorb-iQ (Quantachrome, Boynton Beach, FL, USA). Thermogravimetric analyzer data were studied with a Pyris (Perkin Elmer, Waltham, MA, USA). The water-droplet contact angle were measured by using a contact system (SDC-350, SIN DIN Corporation, Chengdu, China).

\subsection{Formulation}

The domain size (La) and crystalline size (Lc) of the LIG can be calculated from the XRD characteristics using the following equations [18]:

$$
\begin{aligned}
& \mathrm{L}_{\mathrm{a}}=\frac{1.84 \lambda}{\mathrm{B}(2 \theta) \cos \theta} \\
& \mathrm{L}_{\mathrm{c}}=\frac{0.89 \lambda}{\mathrm{B}(2 \theta) \cos \theta}
\end{aligned}
$$

where $B(2 \theta)$ (in radian units) is the full width at half maximum of peaks (002) and (100), and $\lambda$ is the wavelength of the $X$-rays $(\lambda=1.54 \AA$ ).

The normalized Brunauer-Emmett-Teller (BET) surface can be defined as follows [42]:

$$
\frac{\frac{P}{P_{0}}}{V\left(1-\frac{P}{P_{0}}\right)}=\frac{1}{V_{m} C}+\frac{C-1}{V_{m}} \times \frac{P}{P_{0}}
$$

where $P / P_{0}$ is the relative pressure, $V_{m}$ is the volume of the adsorbed gas, and $C$ is the BET constant, which is used to evaluate the change in the volume of adsorption gas according to the pressure change. 


\section{Results \\ 3.1. Morphological Characterization}

Figure 2 shows the FE-SEM images of the pulse-overlapped LIG patterns on the PI. Figure $2 b-e$ show the patterns fabricated at a speed of $20 \mathrm{~mm} / \mathrm{s}$. The LIG surface has a porous structure with the pore sizes ranging from 5 to $8 \mu \mathrm{m}$, which is similar to the pattern fabricated by a $\mathrm{CO}_{2}$ laser with a fluence of $6.6 \mathrm{~J} / \mathrm{cm}^{2}$ [43]. The porous surface structure is likely caused by the escape of gases such as $\mathrm{CO}$ and $\mathrm{H}_{2}$, owing to the localized high temperature and pressure [44]. Figure $2 \mathrm{f}-\mathrm{i}$ shows the patterns fabricated at a laser speed of $40 \mathrm{~mm} / \mathrm{s}$. Owing to the relatively lower dynamic fluence, the micropore structure on the surface disappeared. Most of the peeled surface layers disappeared, revealing a relatively clean surface. This means that the pore radius on the surface was much smaller at the nanometer scale with a lower pressure and temperature than the prepared samples fabricated at a laser scanning speed of $20 \mathrm{~mm} / \mathrm{s}$. Figure $2 \mathrm{j}-\mathrm{m}$ show the patterns fabricated at a speed of $60 \mathrm{~mm} / \mathrm{s}$. At this laser speed, the LIG patterns showed delamination of the surface. We predicted that a relatively faster laser scanning speed would result in more photochemical ablation [45]. As shown in Figure 21-m, the porosity appears to disappear from the LIG patterns. We assumed that when the laser scanning speed was $60 \mathrm{~mm} / \mathrm{s}$, the interaction between the PI and UV laser showed the most effective photo-thermal and chemical effects. Figure $2 \mathrm{n}-\mathrm{q}$ show the patterns fabricated at a speed of $80 \mathrm{~mm} / \mathrm{s}$. Figure 2n,o show that there was a more pronounced delamination effect. A more peeled layer was formed on the surface, and it seems that the photochemical effect on the surface was more dominant than the photo-thermal effect. Figure $2 r-u$ show the patterns fabricated at a laser speed of $100 \mathrm{~mm} / \mathrm{s}$. Figure $2 \mathrm{~b}, \mathrm{c}$ show that the PI surfaces have a lot of delaminated layers [45]. As shown in Figure 2t-u, the thickness and porosity of the LIG patterns greatly decreased owing to the relatively lower dynamic fluence.

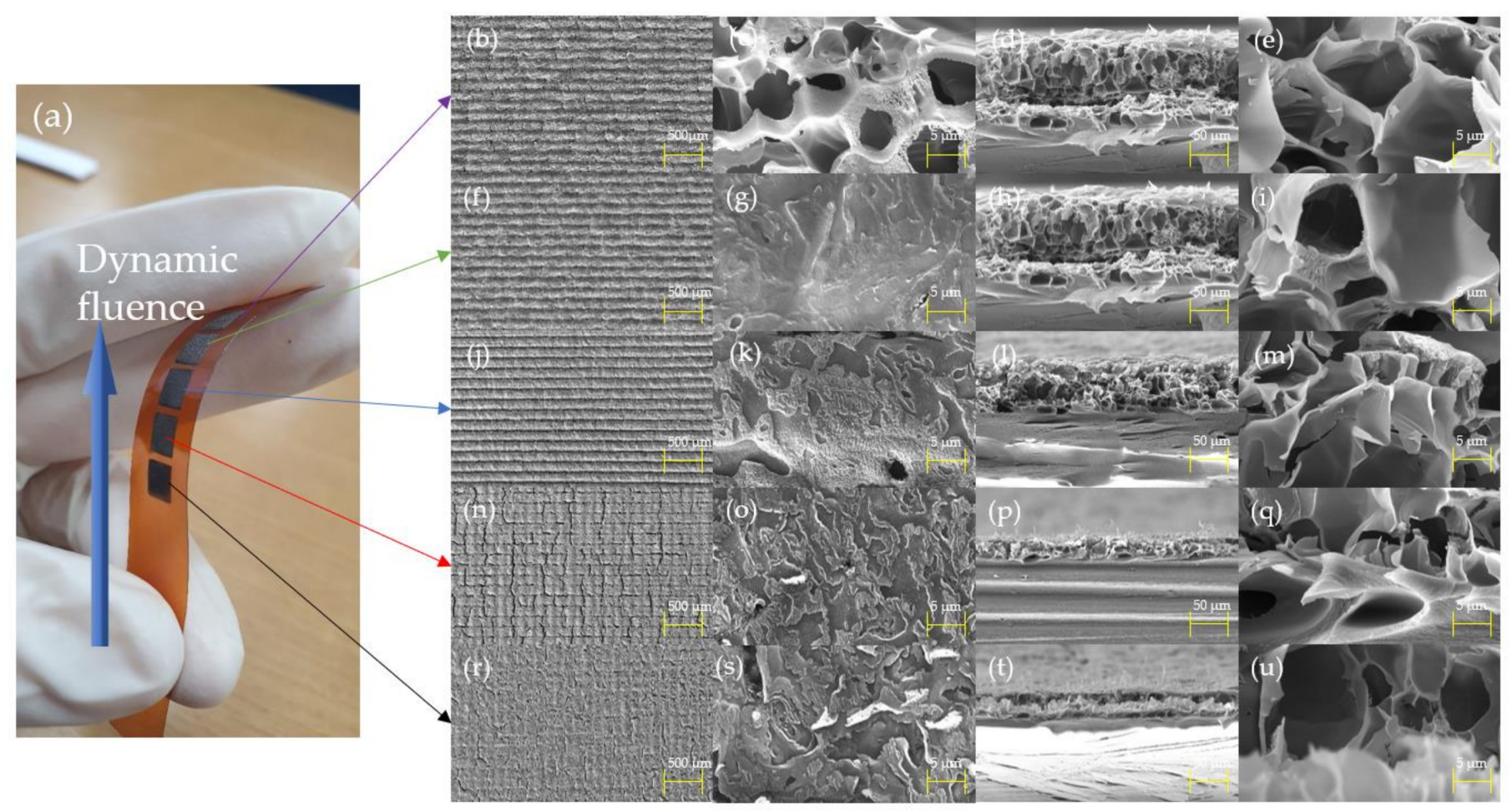

Figure 2. (a) Actual photograph of LIG patterns. FE-SEM images of LIG patterns fabricated at a laser scanning speed of (b-e) $20 \mathrm{~mm} / \mathrm{s},(\mathbf{f}-\mathbf{i}) 40 \mathrm{~mm} / \mathrm{s},(\mathbf{j}-\mathbf{m}) 60 \mathrm{~mm} / \mathrm{s},(\mathbf{n}-\mathbf{q}) 80 \mathrm{~mm} / \mathrm{s}$, and $(\mathbf{r}-\mathbf{u}) 100 \mathrm{~mm} / \mathrm{s}$. 


\subsection{Chemical Characterization}

As indicated in Figure 3a, the Raman spectrum of the LIG patterns presented three characteristic peaks of graphenic carbon [46]. The D band, positioned at $1346 \mathrm{~cm}^{-1}$, is induced by aromatic carbon domains, and when these domains are larger than $2 \mathrm{~nm}$, the peak intensity increases with the number of defects and edges. The G-band at $1580 \mathrm{~cm}^{-1}$ arises from the stretching of $s p^{2}$ carbon bonds in the graphitic materials. The narrowing of the bands implies a transition from amorphous to crystalline states. In addition, the peak intensity ratios of the $I_{G} / I_{D}$ bands are important indicators for understanding defect density. The defect density is related to photo-thermal graphitization, which indicates the transformation to graphene-like structures. As the laser scanning speed decreases, both the band and the indicator $I_{G} / I_{D}$ decrease under our laser conditions. The $2 \mathrm{D}$ peak at $2690 \mathrm{~cm}^{-1}$ is uniquely associated with two-dimensional graphite with randomly stacked graphene sheets along the c-axis. The stronger 2D peak suggests a more complete graphitization of PI and the formation of graphene. The 2D peak increases as the laser scanning speed decreases [47].

(a)

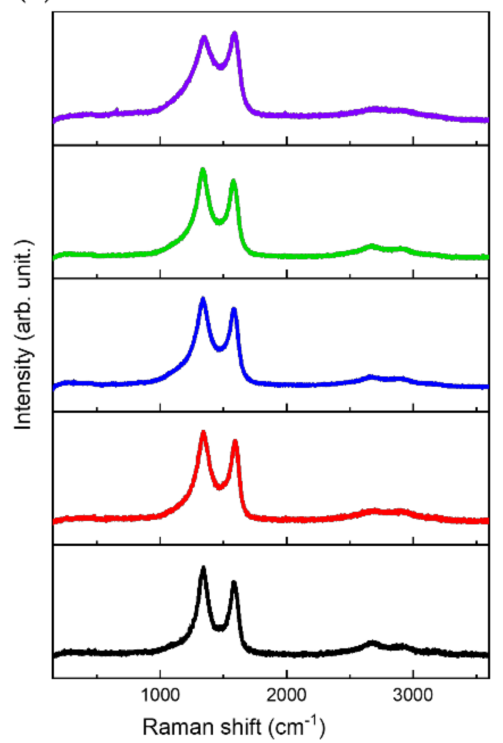

(b)

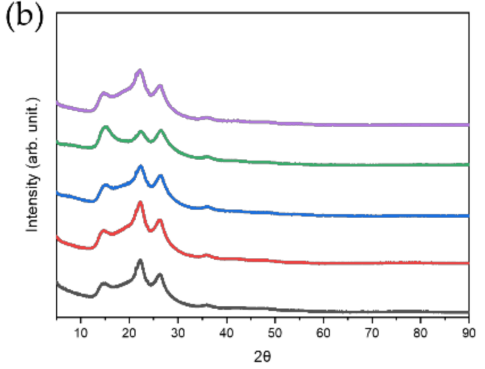

(d)

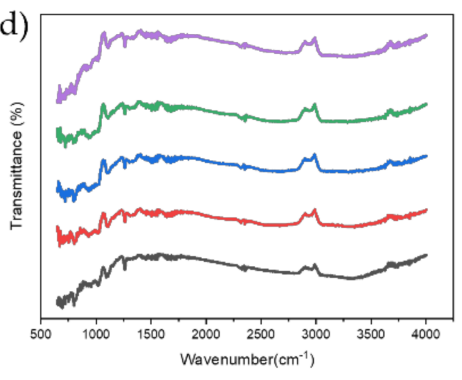

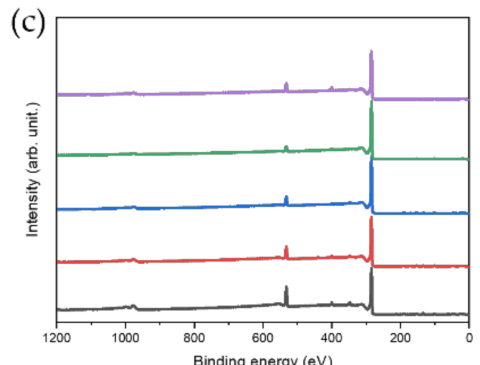

(e)

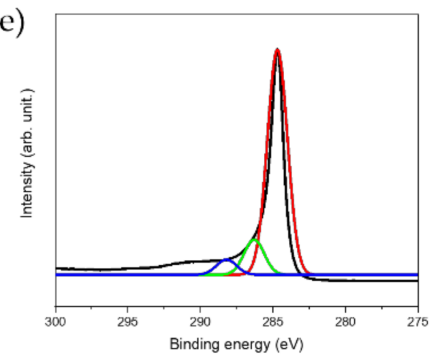

Figure 3. (a) Raman spectra of LIG patterns, (b) XRD results of LIG patterns, (c) XPS characteristics of the LIG patterns according to the laser speed, (c) XPS, (d) FTIR analysis of LIG patterns, (e) XPS C1s data of LIG patterns fabricated at laser speed of $60 \mathrm{~mm} / \mathrm{s}$ (violet: $100 \mathrm{~mm} / \mathrm{s}$, green: $80 \mathrm{~mm} / \mathrm{s}$, blue: $60 \mathrm{~mm} / \mathrm{s}$, red: $40 \mathrm{~mm} / \mathrm{s}$ black: $20 \mathrm{~mm} / \mathrm{s}$ ).

X-ray diffraction analysis was performed to evaluate the spacing between the layers on the LIG heaters. The XRD patterns at scanning speeds of 20, 40, 60, 80, and $100 \mathrm{~mm} / \mathrm{s}$ are shown in Figure $3 \mathrm{~b}$. Three main peaks at all scanning speeds were deconvoluted at $15^{\circ}, 22.3^{\circ}$, and $26^{\circ}$, corresponding to the (001), (002), and (002) planes, indicating that LIG heaters were successfully prepared and uniformly consisted of reduced graphene oxide (RGO). The peaks only show various intensities at $22.3^{\circ}$, the parameter for the degree of graphitization, depending on the scanning speed of the laser $[18,48]$. The typical peak at $14^{\circ}$ was attributed to the formation of oxygen functional groups in the LIG heaters. This corresponds to a d-spacing of $6.3 \AA$, which is larger than that of pristine graphene owing to the existence of oxygen functional groups. The other characteristic peaks indicate the disordered structure and unoxidized carbonaceous materials in the LIG heater, corresponding to a d-spacing of 4 and $3.4 \AA$, respectively $[18,48]$. These results show that the average $d$-spacing agrees well with observed TEM images (Figure S2). The LIG heater with a scanning speed of $40 \mathrm{~mm} / \mathrm{s}$ shows the intense peak at $22.3^{\circ}$, confirming the high degree of graphitization, whereas that with scanning speed of $80 \mathrm{~mm} / \mathrm{s}$ shows the weak peak at $22.3^{\circ}$. Calculating the domain size (La) and crystalline size (Lc) from Equations (1) and (2), 
the corresponding values of Lc and La are $3.91 \mathrm{~nm}$ and $2 \mathrm{~nm}$ for the $15^{\circ}$ peak, $3.76 \mathrm{~nm}$ and $1.92 \mathrm{~nm}$ for the $22.3^{\circ}$ peak, and $6.08 \mathrm{~nm}$ and $3.11 \mathrm{~nm}$ for the $26^{\circ}$ peak. As shown in Figure $3 c-e$, XPS was employed to understand the chemical bonds of the LIG heater. The ratio of the $\mathrm{C} 1 \mathrm{~s}$ peak to the $\mathrm{O} 1 \mathrm{~s}$ peak indicates the formation of oxygen functional groups [49]. The low ratio of the C1s peak to the O1s peak is attributed to the highly oxidized LIG patterns (Figure 3c). The heaters with scanning speeds of $20 \mathrm{~mm} / \mathrm{s}$ and $40 \mathrm{~mm} / \mathrm{s}$ display a relatively low ratio of the C1s peak to the O1s peak, suggesting an increased amount of oxygen functional groups. The C1s spectrum of the heater with a scanning speed of $60 \mathrm{~mm} / \mathrm{s}$ is shown in Figure 3e, which contains three main peaks at $284 \mathrm{eV}(\mathrm{C}=\mathrm{C}$ bonds), $286 \mathrm{eV}$ (C-O bonds), and $289 \mathrm{eV}$ (O-C=O bonds), respectively [50]. The intensity of the $\mathrm{C}-\mathrm{O}$ bonds is relatively higher than that of the pristine graphene, and the heater is determined to be graphene oxide (GO) and can work as a Joule heater with applied voltage. FTIR analysis of LIG heaters is observed in Figure 3d, showing the absence of any intense graphite peaks. Distinguishable intensity peaks of the heaters were observed at $3325,1720,1632,1180$, and $1040 \mathrm{~cm}^{-1}$, corresponding to the stretching of phenolic hydroxyl groups $(-\mathrm{OH})$, carbonyl and carboxyl groups $(\mathrm{C}=\mathrm{O})$, sp2 carbon groups $(\mathrm{C}=\mathrm{C})$, epoxide groups $(\mathrm{C}-\mathrm{O}-\mathrm{C})$, and epoxy groups $(\mathrm{C}-\mathrm{O})$, respectively $[51,52]$. The analysis indicated the presence of GO with little difference depending on the scanning speed of the laser.

The Brunauer-Emmett-Teller (BET) surface area of the LIG heater was measured by N2 adsorption and desorption using a Quantachrome (Autosorb-iQ) from Florida, USA. The specific surface area and pore size of the material were analyzed by adsorbing N2 gas to the sample and measuring the adsorption amount by partial pressure. The normalized BET surface is defined by Equation (3). The specific surface areas for each LIG heater with BET analysis were $116.695 \mathrm{~m}^{2} / \mathrm{g}, 103.357 \mathrm{~m}^{2} / \mathrm{g}, 64.045 \mathrm{~m}^{2} / \mathrm{g}, 44.121 \mathrm{~m}^{2} / \mathrm{g}$, and $15.861 \mathrm{~m}^{2} / \mathrm{g}$, and the average pore diameters were $30.42 \AA, 42.02 \AA, 67.72 \AA, 44.96 \AA$, and $69.86 \AA$, in order of ascending laser fluence. The results show that as the laser fluence increased, the BET surface area decreased (Figure $4 a-d)$. It was found that a high scanning speed shows a significantly lower $\mathrm{V}_{m}$ than the others, and the smaller the specific surface area, the higher the thermal conductivity. The major weight loss of the LIG heaters can be explained based on the decomposition temperature of the internal chemical structure. The thermogravimetric analysis (TGA) results suggest a change in weight of the sample according to the temperature change and show the thermal stability of the sample and the composition ratio of the materials (Figure 4e). In general, a weight loss at approximately $100{ }^{\circ} \mathrm{C}$ is caused by the evaporation of moisture from the sample [53,54]. Water molecules that are easily decomposed by heat exist as hydrogen bonds between the epoxy group and the hydroxyl group, and the weight loss that occurs at $100-400{ }^{\circ} \mathrm{C}$ can be associated with the removal of oxygen-containing functional groups. In this process, water molecules are removed in stages, resulting in weight loss at approximately $180{ }^{\circ} \mathrm{C}$ [55]. Thereafter, the carboxyl and carbonyl groups are gradually removed at a high temperature of $500{ }^{\circ} \mathrm{C}$ [56]. As shown in Figure 4e, TGA in air suggests that increasing the laser fluence improves the thermal stability of the LIG heater. Figure $4 \mathrm{f}$ shows the zeta potential distribution depending on the scanning speed of the laser, confirming the presence of negative charges on the surface of the heaters at all scanning speeds. The negative charges are ascribed to the ionization of the carboxylic acid and phenolic hydroxyl groups observed in the FTIR analysis of GO [57]. The LIG heater with a scanning speed of $60 \mathrm{~mm} / \mathrm{s}$ contains a zeta potential of $-0.3 \mathrm{mV}$, which is the lowest value among the scanning speeds ranging from 20 to $100 \mathrm{~mm} / \mathrm{s}$. Since the heaters with scanning speeds of $80 \mathrm{~mm} / \mathrm{s}$ and $100 \mathrm{~mm} / \mathrm{s}$ have imperfect GO structures, they carry negative charges, resulting in a more negative zeta potential than those with a scanning speed of $60 \mathrm{~mm} / \mathrm{s}$. The heaters with scanning speeds of 20,40, and $60 \mathrm{~mm} / \mathrm{s}$ consist of a 3D carbon network structure of GO, containing many ionizations of the carboxylic acid and phenolic hydroxyl groups, resulting in a negative zeta potential. Since the LIG heaters fabricated at a scanning speed of $60 \mathrm{~mm} / \mathrm{s}$ contain the appropriate ionization of the carboxylic acid and phenolic hydroxyl groups, they display the lowest zeta potential. The result depending on the scanning speed of 
the laser agrees with the XRD and elemental analysis TGA, which reveal the existence of hydrogen and oxygen.

(a)

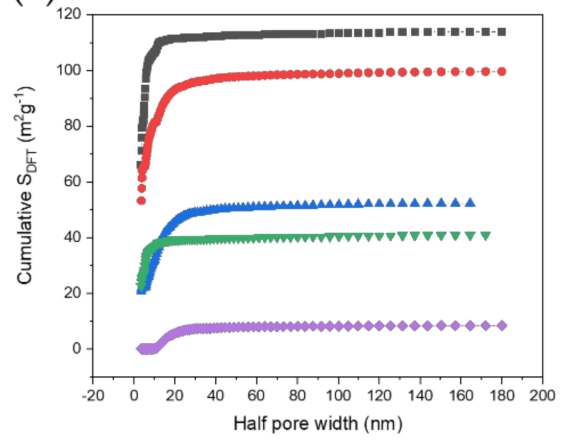

(d)

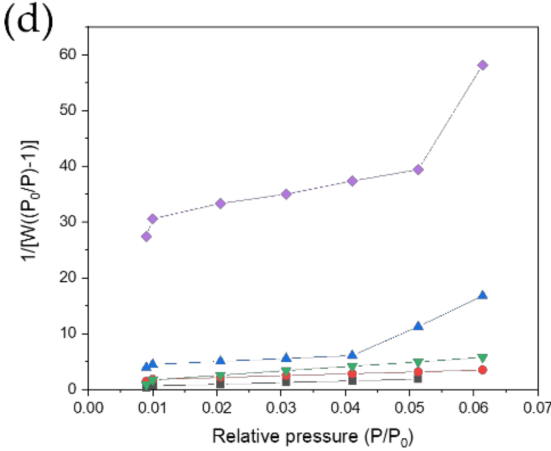

(b)

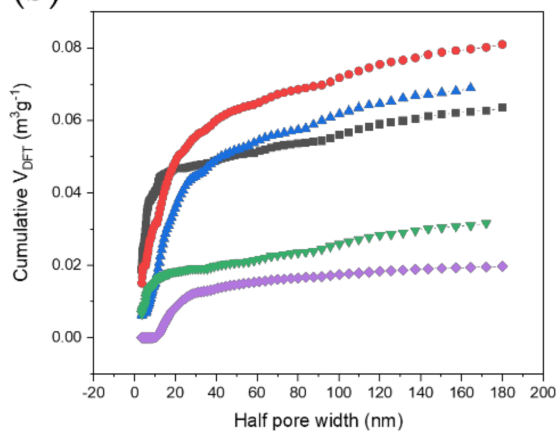

(e)

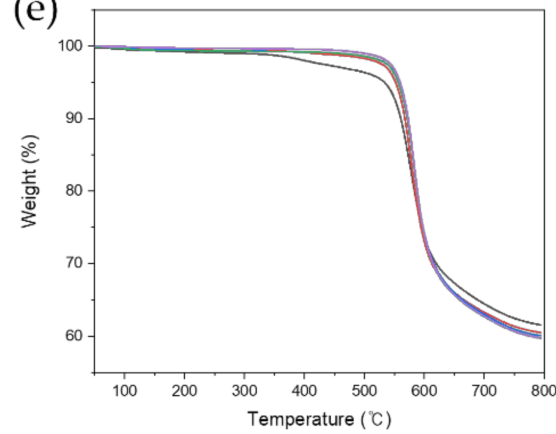

(c)

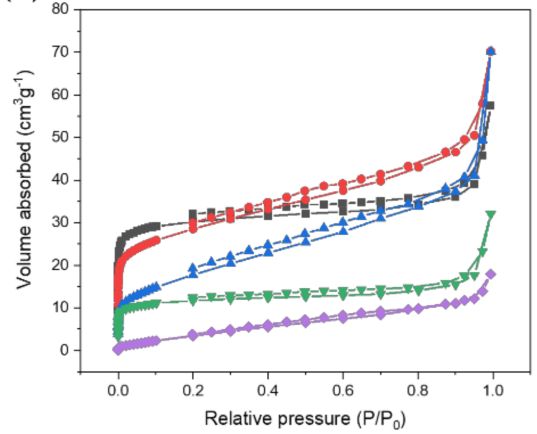

(f)

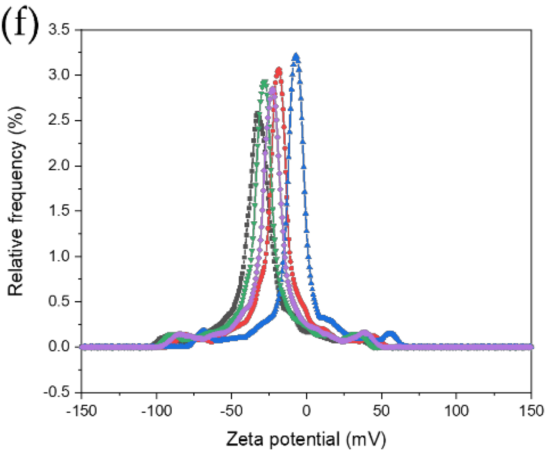

Figure 4. (a) Cumulative surface area and (b) cumulative pore volume derived from nitrogen physisorption data of the prepared LIG patterns fabricated according to laser scanning speed. (c) N2 adsorption-desorption isotherms of LIG patterns fabricated with different laser scanning speeds. (d) Plot of $1 /[\mathrm{W}((\mathrm{W}(\mathrm{Po} / \mathrm{P})-1)]$ and relative pressure for surface area calculation of LIG patterns, (e) TGA curves of LIG patterns, (f) zeta potential distribution curves for LIG patterns (violet: $100 \mathrm{~mm} / \mathrm{s}$, green: $80 \mathrm{~mm} / \mathrm{s}$, blue: $60 \mathrm{~mm} / \mathrm{s}$, red: $40 \mathrm{~mm} / \mathrm{s}$, black: $20 \mathrm{~mm} / \mathrm{s}$ ).

\subsection{Electrical and Thermal Properties of LIG Pattern}

The electrical properties of the LIG heaters were investigated for different laser scanning speeds. As displayed in Figure 5a, the I-V curves for the LIG heaters exhibited a linear relationship, indicating good ohmic behavior in all cases. The heater with a scanning speed of $40 \mathrm{~mm} / \mathrm{s}$ shows the highest slope of the I-V curve because of its good conductance of the pattern. The cyclic bending method was used to observe the electromechanical durability. We measured the change in electrical resistance after every 100 bending cycles, as shown in Figure $5 \mathrm{~b}$. The resistance of the LIG patterns is mostly constant, except for the change in resistance of the LIG patterns fabricated at laser speeds of $80 \mathrm{~mm} / \mathrm{s}$ and $100 \mathrm{~mm} / \mathrm{s}$. This means that the LIG patterns fabricated from the laser scanning speed of 20 to $60 \mathrm{~mm} / \mathrm{s}$ have a stable, well-formed conductive carbon network structure [58]. The resistance change according to bending was performed using a cylinder model with various radius $(\mathrm{r})$ values, and its impact on the heater is summarized in Figure 5c. By decreasing the radius of the cylinder, the resistance shift was measured for our LIG patterns. All the LIG patterns show that the resistance increases slightly as the radius of the cylinder decreases (or the curvature represented by $1 / \mathrm{r}$ increases). The excellent characteristic of the flexibility of the patterns is that they maintain the electrical characteristics after a bending test. The LIG patterns fabricated from laser scanning speeds of $20 \mathrm{~mm} / \mathrm{s}$ and $40 \mathrm{~mm} / \mathrm{s}$ showed a flat slope, which indicates good flexibility [59]. 
(a)

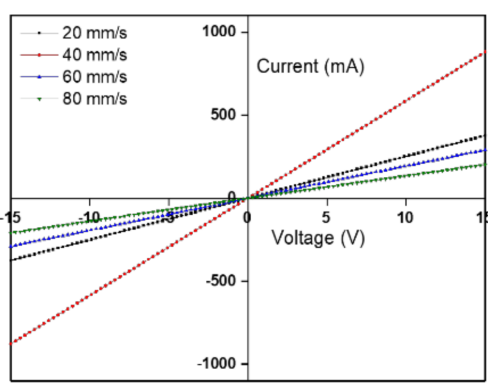

(b)
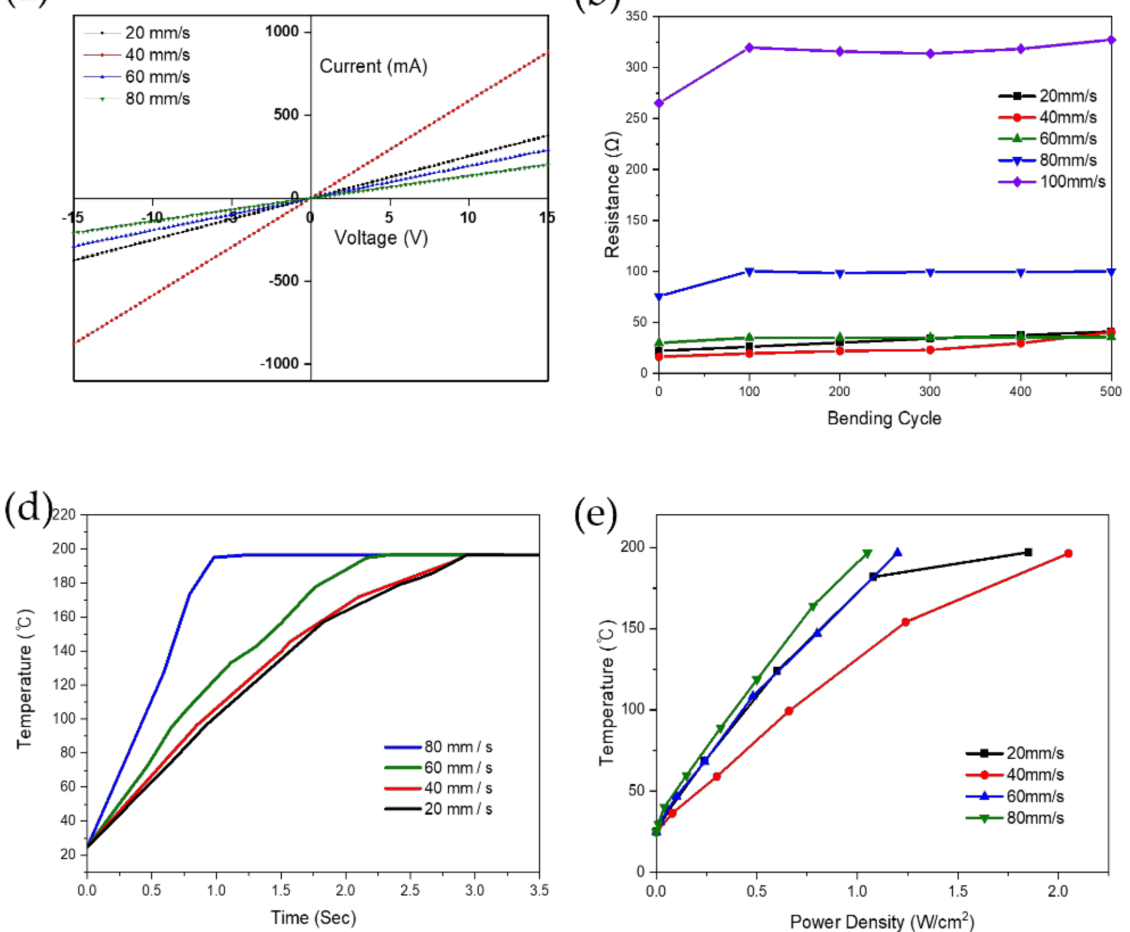

(e)

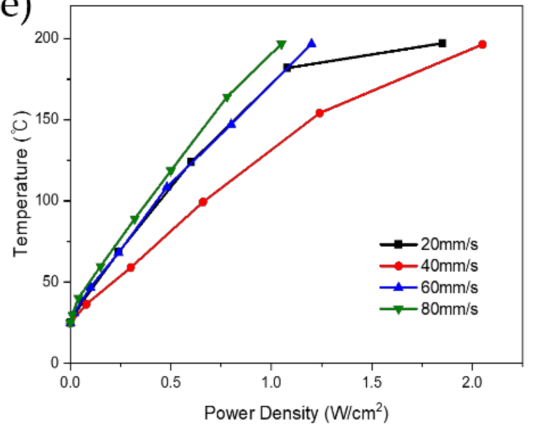

(c)

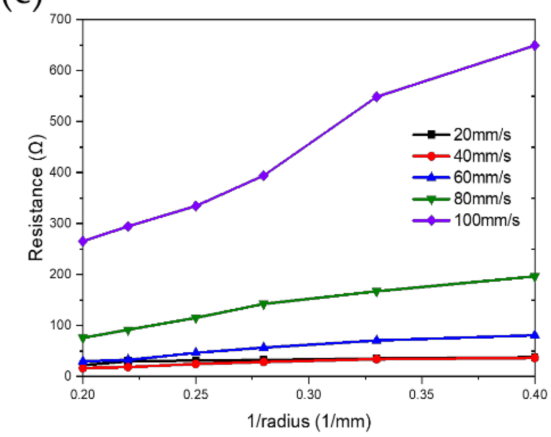

(f) 200

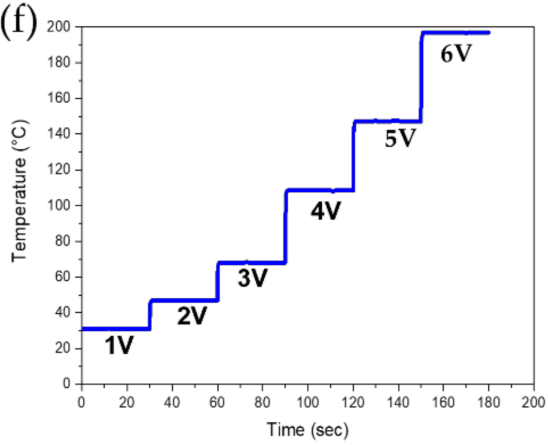

Figure 5. (a) I-V curve measurement of LIG patterns fabricated according to laser scanning speed. (b) Change in electrical resistance after cyclic bending. (c) Change in resistance as LIG patterns are bent by a cylinder of different radius. (d) Timedependent characteristics of transient time to reach $200^{\circ} \mathrm{C}$ under $12 \mathrm{~V}$. (e) Temperature as a function of the applied electrical power density for LIG heaters. (f) Temperature evolution of LIG heaters at stepwise voltage rise from 1 to $6 \mathrm{~V}$.

The thermal performance studies obtained for the LIG heaters with an area of $100 \mathrm{~mm}^{2}$ are shown in Figure 5d. As shown in Figures S3 and S4, it was found that the size of each pattern and resistance between the electrode and LIG patterns are important factors for the heater. Our LIG heaters offer a quick response to the voltage loads, and the LIG heater fabricated at $80 \mathrm{~mm} / \mathrm{s}$ can reach approximately $200^{\circ} \mathrm{C}$ under $12 \mathrm{~V}$ within a very short period of time (less than $1.5 \mathrm{~s}$ ) - this is the best thermal performance as far as we are aware $[12-17,37,60]$. The temperature changes depending on the power density of all the LIG-heaters are shown in Figure 5e. When the voltage was increased, all LIG heaters demonstrated an almost monotonous linear behavior [12]. The power densities to reach the saturation temperature of each heater are $20 \mathrm{~mm} / \mathrm{s}\left(1.2 \mathrm{~W} / \mathrm{cm}^{2}\right.$ at $\left.5 \mathrm{~V}\right), 40 \mathrm{~mm} / \mathrm{s}$ $\left(2.05 \mathrm{~W} / \mathrm{cm}^{2}\right.$ at $\left.5 \mathrm{~V}\right), 60 \mathrm{~mm} / \mathrm{s}\left(1.2 \mathrm{~W} / \mathrm{cm}^{2}\right.$ at $\left.6 \mathrm{~V}\right)$, and $80 \mathrm{~mm} / \mathrm{s}\left(1.05 \mathrm{~W} / \mathrm{cm}^{2}\right.$ at $\left.7 \mathrm{~V}\right)$. Therefore, our LIG heater can provide not only a quick response to $200{ }^{\circ} \mathrm{C}$ (less than $3 \mathrm{~s}$ ) but also high electrothermal efficiency with low power density.

From the relatively constant resistance-current behavior shown in Figure 5b, it can be observed that the LIG heaters exhibit ohmic behavior. Both the current and resistance show drastic changes when voltage is applied. They remained almost constant while the voltage was applied. As seen in Figure $5 \mathrm{f}$, a step-like increase in temperature from 1 to $6 \mathrm{~V}$ was recorded to evaluate the stability and Joule heating performance of the LIG heater fabricated at a scanning speed of $60 \mathrm{~mm} / \mathrm{s}$, showing the best electrical properties. The test indicates six repeated cycles of maintaining the increased temperature for $30 \mathrm{~s}$ and then increasing the voltage applied to the heater to ensure its stability. It takes very little time to reach the saturation temperature, implying its outstanding rapid thermal change.

After studying the structural, electrical, and thermal properties of the LIG heaters, our heaters were also analyzed for electrothermal stability by monitoring the temperature change with a bending test $[12,61]$. Figure 6 shows the temperature variations of the heaters with a size of $100 \mathrm{~mm}^{2}$ during $16,000 \mathrm{~s}$ of bending with a bending radius of 10 
$\mathrm{mm}$ and a total frequency of $0.5 \mathrm{~Hz}$. The electric power was set to $2 \mathrm{~W}$ to achieve a steady temperature of $53{ }^{\circ} \mathrm{C}$, according to the electrothermal experiments in Figure 6 on a rectangular $\left(100 \mathrm{~mm}^{2}\right)$ heater. Under these conditions, an electric power of $2 \mathrm{~W}$ was applied to the LIG patterns for $20 \mathrm{~s}$ and discontinued for another $20 \mathrm{~s}$ during 400 repeated cycle tests. The maximum changes in temperature reported were below $13.7^{\circ} \mathrm{C}$, resulting in a relative variation of temperature under $3 \%$, following the periodic bending of the substrate. The cycle test showed outstanding stability and durability without any degradation under repeated bending.

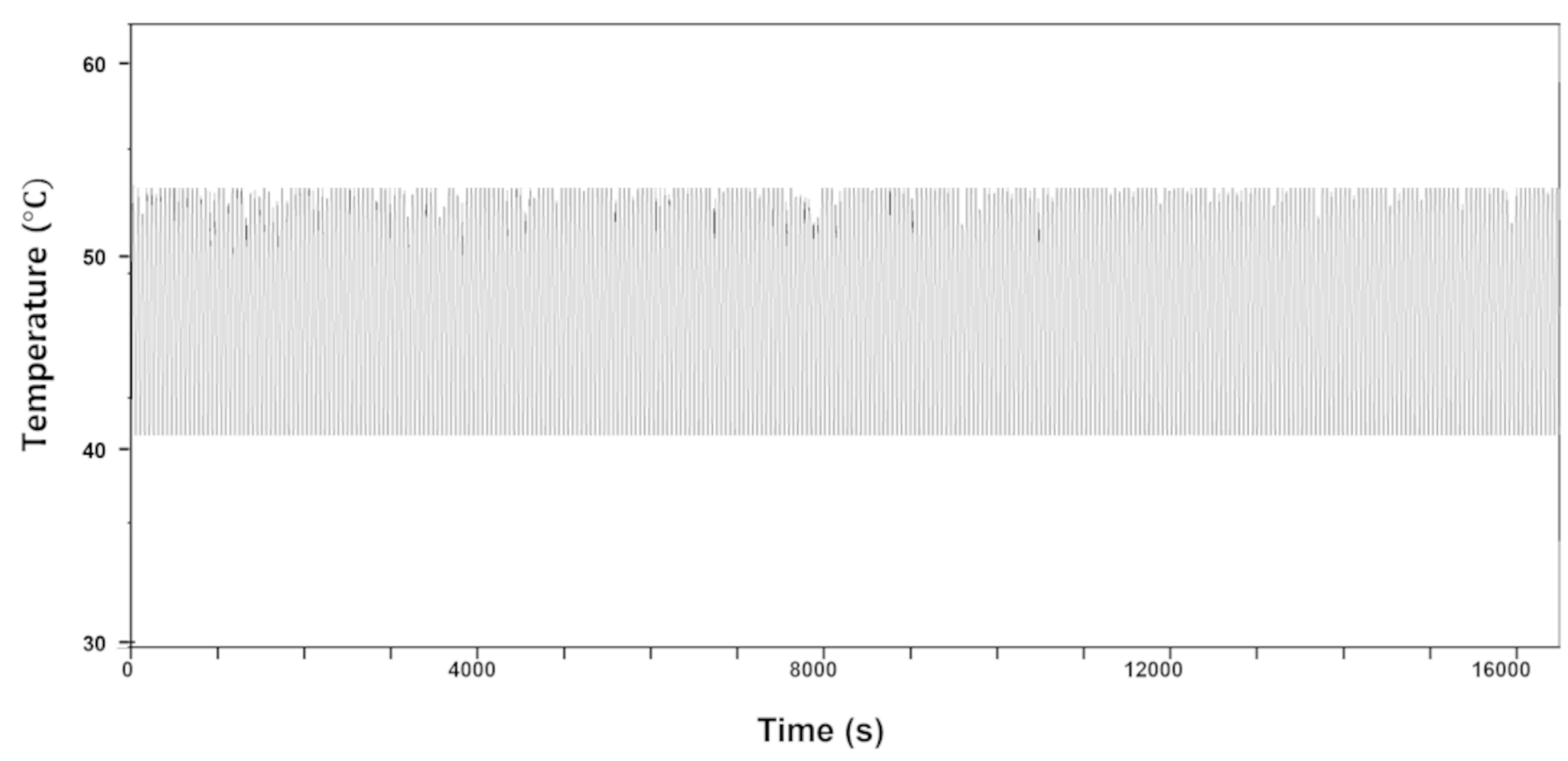

Figure 6. Cycle test for temperature change of LIG heater pad.

\subsection{Application of LIG Heater for De-Icing}

To investigate the performance of the heater for de-icing applications, we dropped $3 \mathrm{~mL}$ of water on the LIG heater and froze it. Figure $7 \mathrm{a}-\mathrm{c}$ shows the temperature change plot for de-icing. We applied $12 \mathrm{~V}$ to observe Joule heating for the thermal performance of the LIG heater when iced. Melting water was observed through Joule heating of the LIG heater. As the temperature was rapidly increased to $49^{\circ} \mathrm{C}$, the LIG heater with a scanning speed of $20 \mathrm{~mm} / \mathrm{s}$ showed the best heating performance, with water melting after $60 \mathrm{~s}$. The LIG heater with a scanning speed of $40 \mathrm{~mm} / \mathrm{s}$ melted the water earlier than that at a scanning speed of $60 \mathrm{~mm} / \mathrm{s}$. It reached the highest temperature of $78.2{ }^{\circ} \mathrm{C}$ among the heaters. The frozen water on the LIG heater with a scanning speed of $60 \mathrm{~mm} / \mathrm{s}$ gradually melted as the temperature increased from 26.3 to $61.5^{\circ} \mathrm{C}$. After $83 \mathrm{~s}$, the frozen water was completely removed from the LIG heater.

As shown in Figure 7d, the contact angle of the LIG heater was analyzed depending on the laser scanning speed from 20 to $100 \mathrm{~mm} / \mathrm{s}$. The heater fabricated at a lower scanning speed displayed more hydrophilicity. This is because the surface containing more oxygen functional groups in contact with water increases [62]. Figure 7e indicates the de-icing test of our LIG heater with real images of frozen and melted water. 
(a)

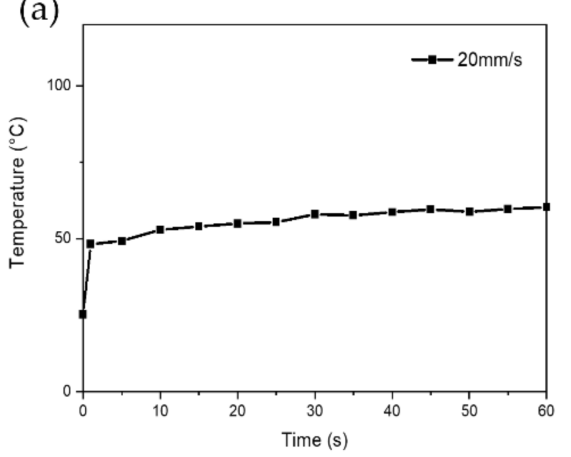

(d)

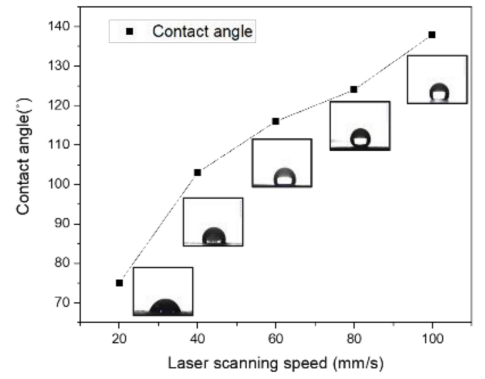

(b)

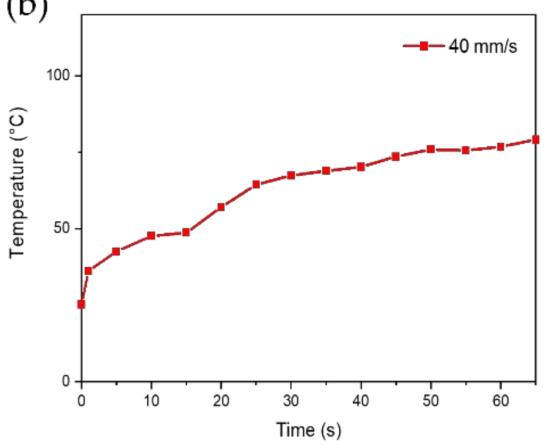

(c)

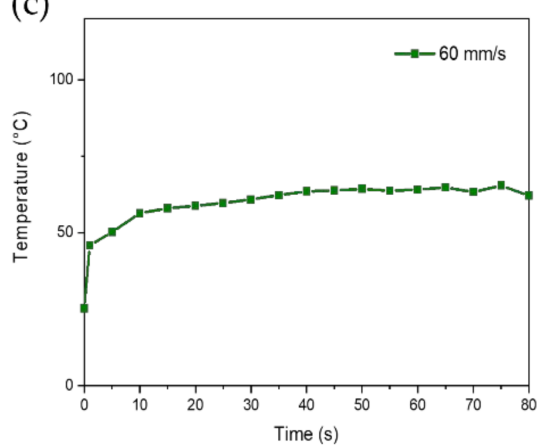

(e)
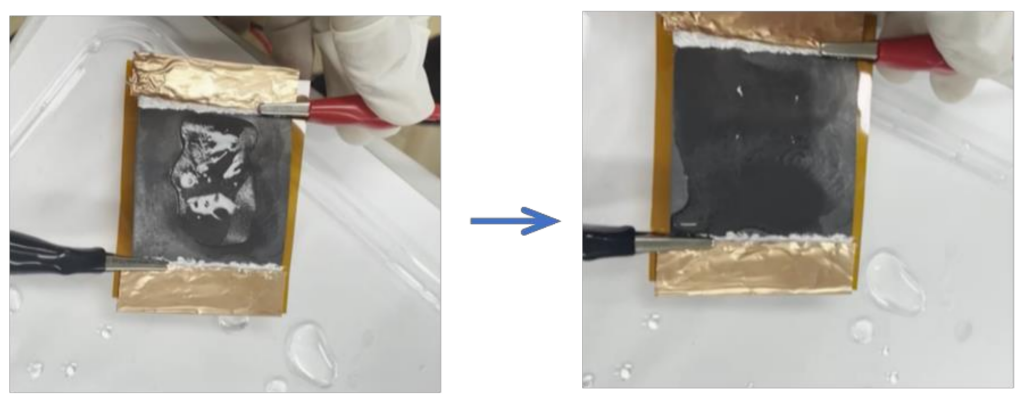

Figure 7. Temperature change plot for de-icing of LIG heater $(50 \mathrm{~mm} \times 50 \mathrm{~mm})$ fabricated at a laser scanning speed of (a) $20 \mathrm{~mm} / \mathrm{s}$, (b) $40 \mathrm{~mm} / \mathrm{s}$, and (c) $60 \mathrm{~mm} / \mathrm{s}$ during Joule heating of $12 \mathrm{~V}$. (d) Contact angle depending on the laser scanning speed. (e) De-icing test of water droplet $(3 \mathrm{~mL})$ with LIG heater.

In addition, a de-icing experiment was conducted using two different LIG heater pads for de-icing $3 \mathrm{~mL}$ of ice. We applied $12 \mathrm{~V}$ to observe the water melting in the Kapton tape/LIG heater and Kapton tape/aluminum foil/LIG heater, as shown in Figure 8a and (b). In both samples, the ice gradually melted as the temperature increased from 26.3 to $149.2^{\circ} \mathrm{C}$. Aluminum foil was selected as the optimal substrate with an outstanding thermal conductivity. Figure S6 shows that the LIG heater pad/aluminum foil shows sufficient performance to convert water into steam. To protect the LIG heater surface with high roughness, we shielded the LIG surface with Kapton tape. Attaching the Kapton tape enhances the accumulation of the heat generated during Joule heating in the large pores inside the high rough LIG heater, which causes a rapid temperature rise, as depicted in Figure $8 \mathrm{c}$. With $3 \mathrm{~mL}$ of water frozen on the Kapton tape/LIG, the state change of water occurred through Joule heating. The surface temperature reached approximately $100{ }^{\circ} \mathrm{C}$ within a few seconds. The ice gradually melted as the temperature increased from 26.3 to $149.2{ }^{\circ} \mathrm{C}$. After approximately $40 \mathrm{~s}$, the ice was completely removed from the Kapton tape/LIG heater, as shown in Figure 8d. These two experiments indicate the LIG heater as a potential prospect for de-icing systems. 
(a)

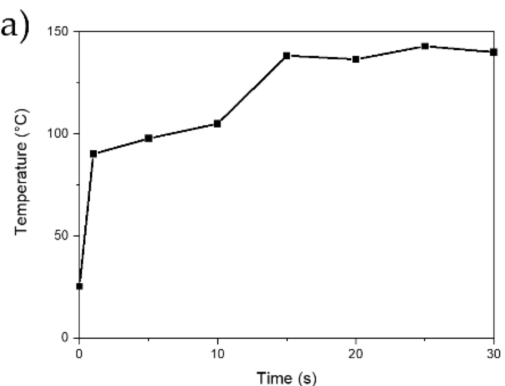

(d)

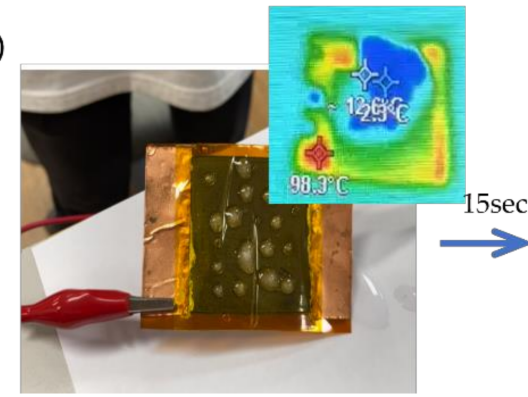

(b)
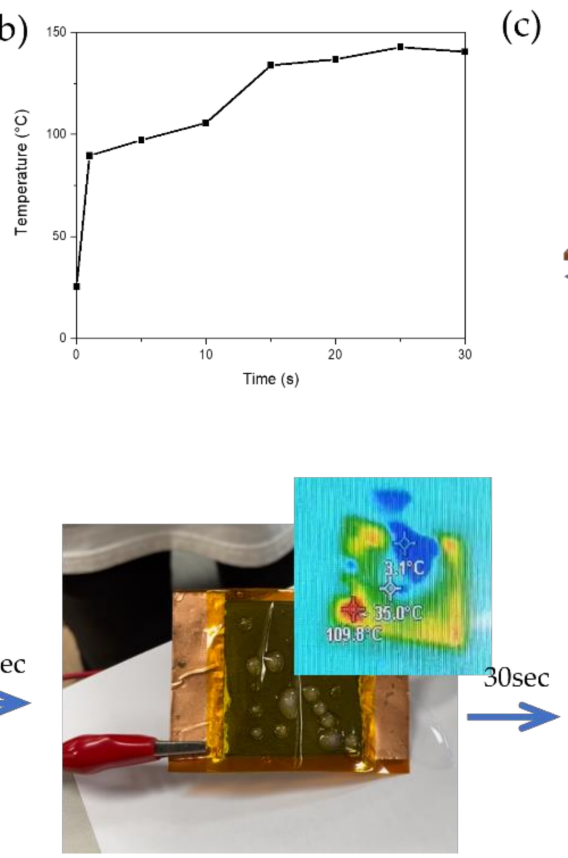

(c)
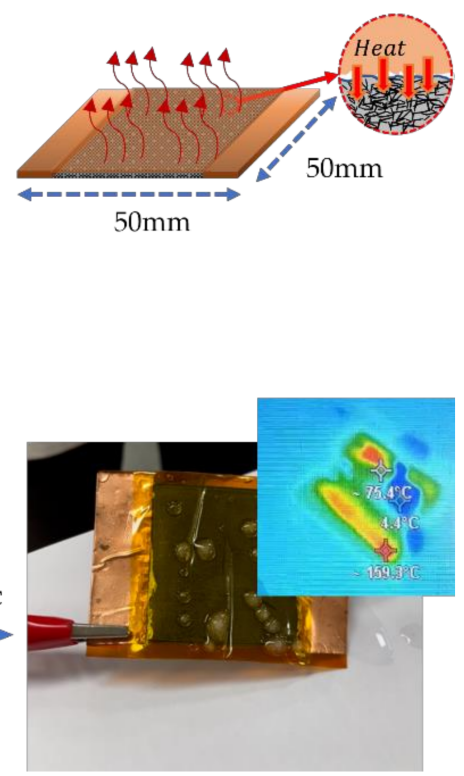

Figure 8. Joule heating (12 V) by attaching Kapton tape on LIG heater $(50 \mathrm{~mm} \times 50 \mathrm{~mm})$ : (a) de-icing test $(1.5 \mathrm{~mL})$ with Kapton/LIG heater, (b) de-icing test $(1.5 \mathrm{~mL})$ with Kapton/aluminum foil/LIG heater. (c) Schematic of LIG heater for heat accumulation in pore structure and roughness pattern. (d) De-icing test of water droplet $(3 \mathrm{~mL})$ with Kapton tape/LIG heater.

\section{Conclusions}

Although LIG has an immense potential in the electro-thermal properties for electronic devices, there is limited research on LIG-based electrothermal applications such as a wearable heat pad and de-icing applications using the electrothermal effect based on localized Joule heating. We report LIG electro-thermal heaters fabricated by a $355 \mathrm{~nm}$ second UV pulsed laser according to the laser scanning speed. The defective abundant and flexible LIG patterns were investigated by FE-SEM, TEM, Raman spectroscopy, TGA, XPS, $\mathrm{XRD}, \mathrm{BET}$, and contact angle measurement.

In summary, the following conclusions can be drawn from the results of this study.

(a) Our LIG heater shows excellent characteristics such as its high porosity, light weight, and small LIG pattern thickness. We adopted laser direct writing (LDW) to irradiate the substrates with computer-aided 2D CAD data for printed electronics under ambient conditions.

(b) All flexible LIG heaters fabricated according to the laser scanning speed showed fast response times, reaching a high thermal temperature of $190{ }^{\circ} \mathrm{C}$ within $3 \mathrm{~s}$. The LIG heater demonstrated a rapid response time, reaching equilibrium within less than $3 \mathrm{~s}$, and achieving temperatures up to $190^{\circ} \mathrm{C}$ using relatively low DC voltages of approximately $10 \mathrm{~V}$.

(c) The LIG heater pad exhibited good flexibility and durability in the bending test. The maximum reported temperature changes were below $13.7^{\circ} \mathrm{C}$, resulting in a relative variation of temperature under $3 \%$, following the periodic bending of the substrate during 16,000 s of bending with a bending radius of $10 \mathrm{~mm}$ and a frequency of $0.5 \mathrm{~Hz}$.

(d) We applied our LIG heater pad for the purpose of de-icing to demonstrate its excellent performance.

Supplementary Materials: The following are available online at https:/ / www.mdpi.com/article/10.3 390/nano11113093/s1, Table S1: Specifications of the 355 nm UV pulsed laser, Table S2. Laser beam condition, Figure S1: The various LIG patterns fabricated on polyimide; (a) Heater patterns on PI at scanning speed of 20,40,60, 80, and $100 \mathrm{~mm} / \mathrm{s}$, (b) Printed circuit board patterns on PI at bending 
state, (c) Electrode patterns fabricated at scanning speed of 20, 40, 60, 80, and $100 \mathrm{~mm} / \mathrm{s}$, Figure S2: TEM images of LIG patterns fabricated at scanning speed of $60 \mathrm{~mm} / \mathrm{s}$; (a) $500 \mathrm{~nm}$, (b) $100 \mathrm{~nm}$, (c) $10 \mathrm{~nm}$ scale bar, Figure S3: Electrothermal test of the flexible LIG heater $\left(150 \mathrm{~mm}^{2}\right)$ without silver paste; (a) 1-12 V voltage applied to LIG heater using the power supply, (b-m) Infrared image of the LIG heater (27.5-196.4 $\left.{ }^{\circ} \mathrm{C}\right)$, Figure S4: The temperature-voltage curve of LIG heater; (a) Sample size $40 \mathrm{~mm} \times 2.5 \mathrm{~mm}$ LIG heater, and (b) Sample size $30 \mathrm{~mm} \times 5 \mathrm{~mm}$ LIG heater. The temperaturevoltage curve for the same sample with the existence of silver paste at (c) scanning speed of $20 \mathrm{~mm} / \mathrm{s}$, (d) scanning speed of $40 \mathrm{~mm} / \mathrm{s}$, (e) scanning speed of $60 \mathrm{~mm} / \mathrm{s}$, and (f) scanning speed of $80 \mathrm{~mm} / \mathrm{s}$, Figure S5: Resistance (blue) and current (red) over time speed for voltages of $10 \mathrm{~V}$ : LIG heater fabricated according to laser scanning (a) $20 \mathrm{~mm} / \mathrm{s}$, (b) $40 \mathrm{~mm} / \mathrm{s}$, (c) $60 \mathrm{~mm} / \mathrm{s}$, and (d) $80 \mathrm{~mm} / \mathrm{s}$, Figure S6: Evaporation test of water droplet $(0.05 \mathrm{~mL})$ with LIG heater pad/aluminum foil.

Author Contributions: Conceptualization, J.-U.L. and C.-W.L.; methodology, J.-U.L., C.-W.L. and S.-C.C.; software, C.-W.L. and S.-C.C.; validation, J.-U.L. and C.-W.L.; formal analysis, J.-U.L.; investigation, B.-S.S.; resources, J.-U.L. and C.-W.L.; data curation, S.-C.C.; writing-original draft preparation, J.-U.L., C.-W.L. and S.-C.C.; writing-review and editing, B.-S.S.; visualization, J.-U.L., C.-W.L. and S.-C.C.; supervision, B.-S.S.; project administration, B.-S.S.; funding acquisition, B.-S.S. All authors have read and agreed to the published version of the manuscript.

Funding: This research received no external funding.

Data Availability Statement: The data presented in this study are available on request from the corresponding author.

Acknowledgments: This research was also supported by the Basic Science Research Program through a National Research Foundation of Korea (NRF) grant funded by the Ministry of Education (2018R1D1A3B07045662). This work was supported by BK21 FOUR Program by Pusan National University Research Grant, 2020. This work was supported by the Technology Innovation Program (P0008763) funded by the Ministry of Trade, Industry, and Energy (MOTIE, Korea).

Conflicts of Interest: The authors declare no conflict of interest.

\section{References}

1. Geim, A.K.; Novoselov, K.S. The rise of graphene. Nat. Mater. 2007, 6, 183-191. [CrossRef] [PubMed]

2. Stankovich, S.; Dikin, D.A.; Dommett, G.H.; Kohlhaas, K.M.; Zimney, E.J.; Stach, E.A.; Piner, R.D.; Nguyen, S.T.; Ruoff, R.S. Graphene-based composite materials. Nature 2006, 442, 282-286. [CrossRef]

3. Stoller, M.D.; Park, S.; Zhu, Y.; An, J.; Ruoff, R.S. Graphene-based ultracapacitors. Nano Lett. 2008, 8, 3498-3502. [CrossRef]

4. Xiang, Q.; Yu, J.; Jaroniec, M. Graphene-based semiconductor photocatalysts. Chem. Soc. Rev. 2012, 41, 782-796. [CrossRef]

5. Spannhake, J.; Schulz, O.; Helwig, A.; Krenkow, A.; Müller, F.; Doll, T. High-temperature MEMS heater platforms: Long-term performance of metal and semiconductor heater materials. Sensors 2006, 6, 405-419. [CrossRef]

6. Vertuccio, L.; Santis, F.D.; Pantani, R.; Lafdi, K.; Guadagno, L. Effective de-icing skin using graphene-based flexible heater. Compos. Part B Eng. 2019, 162, 600-610. [CrossRef]

7. Guadango, L.; Foglia, F.; Pantani, R.; Romero-Sanchez, M.D.; Calderon, B.; Vertuccio, L. Low-Voltage Icing Protection Film for Automotive and Aeronautical Industries. Nanomaterials 2020, 10, 1343. [CrossRef]

8. Wang, X.; You, H.; Liu, F.; Li, M.; Wan, L.; Li, S.; Li, Q.; Xu, Y.; Tian, R.; Yu, Z.; et al. Large-Scale Synthesis of Few-Layered Graphene using CVD. Chem. Vap. Depos. 2009, 15, 53-56. [CrossRef]

9. Munoz, R.; Gomez-Alexiandre, C. Review of CVD Synthesis of Graphene. Chem. Vap. Depos. 2013, 19, 297-322. [CrossRef]

10. Eigler, S.; Enzelberger-Heim, M.; Grimm, S.; Hofmann, P.; Kroener, W.; Geworski, A.; Dotzer, C.; Rockert, M.; Xiao, J.; Papp, C.; et al. Wet Chemical Synthesis of Graphene. Adv. Mater. 2013, 25, 3583-3587. [CrossRef]

11. Cheng, Z.; Zhou, Q.; Wang, C.; Li, Q.; Wang, C.; Fang, Y. Toward Intrinsic Graphene Surfaces: A Systematic Study on Thermal Annealing and Wet-Chemical Treatment of $\mathrm{SiO}_{2}$-Supported Graphene Devices. Nano Lett. 2011, 11, 767-771. [CrossRef] [PubMed]

12. Romero, F.J.; Rivadeneyra, A.; Oritz-Gomez, I.; Salinas, A.; Godoy, A.; Morales, D.P.; Rodriguez, N. Inexpensive Graphene Oxide Heaters Lithographed by Laser. Nanomaterials 2019, 9, 1184. [CrossRef] [PubMed]

13. Meng, X.; Chen, T.; Li, Y.; Liu, S.; Pan, H.; Ma, Y.; Chen, Z.; Zhang, Y.; Zhu, S. Assembly of carbon nanodots in graphene-based composite for flexible electro-thermal heater with ultrahigh efficiency. Nano Res. 2019, 2, 2498-2508. [CrossRef]

14. Zhang, T.Y.; Zhao, H.M.; Wang, D.Y.; Wang, Q.; Pang, Y.; Deng, N.Q.; Cao, H.W.; Yang, Y.; Ren, T.L. A super flexible and custom-shaped graphene heater. Nanoscale 2017, 9, 14357-14363. [CrossRef] [PubMed]

15. Lin, S.Y.; Zhang, T.Y.; Lu, Q.; Wang, D.; Yang, Y.; Wu, X.M.; Ren, T.L. High-performance graphene-based flexible heater for wearable applications. RSC Adv. 2017, 7, 27001-27006. [CrossRef]

16. Sui, D.; Huang, Y.; Huang, L.; Liang, J.; Ma, Y.; Chen, Y. Flexible and transparent electrothermal film heaters based on graphene materials. Small 2011, 7, 3186-3192. [CrossRef] 
17. Kang, J.; Jang, Y.; Kim, Y.; Cho, S.H.; Suhr, J.; Hong, B.H.; Choi, J.B.; Byun, D. An Ag-grid/graphene hybrid structure for large-scale, transparent, flexible heaters. Nanoscale 2015, 7, 6567-6573. [CrossRef]

18. Lin, J.; Peng, Z.; Liu, Y.; Ruiz-Zepeda, F.; Ye, R.; Samuel, E.L.G.; Yacaman, M.J.; Yakobson, B.I.; Tour, J.M. Laser-induced porous graphene films from commercial polymers. Nat. Commun. 2014, 5, 5714. [CrossRef]

19. Nasser, J.; Lin, J.; Zhang, L.; Sodano, H.A. Laser induced graphene printing of spatially controlled super-hydrophobic/hydrophilic surfaces. Carbon 2020, 162, 570-578. [CrossRef]

20. Gupta, A.; Holoidovsky, L.; Thamaraiselvan, C.; Thakur, A.K.; Singh, S.P.; Meijler, M.M.; Arnusch, C.J. Silver-doped laser-induced graphene for potent surface antibacterial activity and anti-biofilm action. Chem. Commun. 2019, 55, 6890-6893. [CrossRef]

21. Ye, R.; Peng, Z.; Wang, T.; Xu, Y.; Zhang, J.; Li, Y.; Nilewski, L.G.; Lin, J.; Tour, J.M. In Situ Formation of Metal Oxide Nanocrystals Embedded in Laser-Induced Graphene. Am. Chem. Soc. Nano 2015, 9, 9244-9251. [CrossRef]

22. Garland, N.T.; McLamore, E.S.; Cavallaro, N.D.; Mendivelso-Perez, D.; Smith, E.A.; Jing, D.; Claussen, J.C. Flexible Laser-Induced Graphene for Nitrogen Sensing in Soil. Am. Chem. Soc. Appl. Mater. Interfaces 2018, 10, 39124-39133. [CrossRef]

23. Cao, L.; Zhu, S.; Pan, B.; Dai, X.; Zhao, W.; Liu, Y.; Xie, W.; Kuang, Y.; Liu, X. Stable and durable laser-induced graphene patterns embedded in polymer substrates. Carbon 2020, 163, 85-94. [CrossRef]

24. Duy, L.X.; Peng, Z.; Li, Y.; Zhang, J.; Ji, Y.; Tour, J.M. Laser-induced graphene fibers. Carbon 2018, 126, 472-479. [CrossRef]

25. Li, L.; Zhang, J.; Peng, Z.; Li, Y.; Gao, C.; Ji, Y.; Ye, R.; Kim, N.D.; Zhong, Q.; Yang, Y.; et al. High-Performance Pseudocapacitive Microsupercapacitors from Laser-Induced Graphene. Adv. Mater. 2015, 28, 838-845. [CrossRef]

26. Peng, Z.; Lin, J.; Ye, R.; Samuel, E.L.; Tour, J.M. Flexible and stackable laser-induced graphene supercapacitors. Am. Chem. Soc. Appl. Mater. Interfaces 2015, 7, 3414-3419. [CrossRef] [PubMed]

27. Luong, D.X.; Yang, K.; Yoon, J.; Singh, S.P.; Wang, T.; Arnusch, C.J.; Tour, J.M. Laser-Induced Graphene Composites as Multifunctional Surfaces. Am. Chem. Soc. Nano 2019, 13, 2579-2586. [CrossRef] [PubMed]

28. Tao, L.Q.; Tian, H.; Liu, Y.; Ju, Z.Y.; Pang, Y.; Chen, Y.Q.; Wang, D.Y.; Tian, X.G.; Yan, J.C.; Deng, N.Q.; et al. An intelligent artificial throat with sound-sensing ability based on laser induced graphene. Nat. Commun. 2017, 8, 14579. [CrossRef]

29. Stanford, M.G.; Li, J.T.; Chyan, Y.; Wang, Z.; Wang, W.; Tour, J.M. Laser-Induced Graphene Triboelectric Nanogenerators. Am. Chem. Soc. Nano 2019, 13, 7166-7174. [CrossRef]

30. Lee, K.J.; Jun, B.H.; Kim, T.H.; Joung, J. Direct synthesis and inkjetting of silver nanocrystals toward printed electronics. Nanotechnology 2006, 17, 2424. [CrossRef]

31. Kang, J.S.; Kim, H.S.; Ryu, J.; Hahn, H.T.; Jang, S.; Joung, J.W. Inkjet printed electronics using copper nanoparticle ink. J. Mater. Sci. Mater. Electron. 2010, 21, 1213-1220. [CrossRef]

32. Shin, D.H.; Woo, S.; Yem, H.; Cha, M.; Cho, S.; Kang, M.; Jeong, S.; Kim, Y.; Kang, K.; Piao, Y. A Self-Reducible and Alcohol-Soluble Copper-Based Metal-Organic Decomposition Ink for Printed Electronics. Am. Chem. Soc. Appl. Mater. Interfaces 2014, 6, 3312-3319. [CrossRef]

33. Ren, H.M.; Guo, Y.; Huang, S.Y.; Zhang, K.; Yuen, M.M.F.; Fu, X.Z.; Yu, S.; Sun, R.; Wong, C.P. One-Step Preparation of Silver Hexagonal Microsheets as Electrically Conductive Adhesive Fillers for Printed Electronics. Am. Chem. Soc. Appl. Mater. Interfaces 2015, 7, 13685-13692. [CrossRef] [PubMed]

34. Luo, C.; Tian, B.; Liu, Q.; Feng, Y.; Wu, F. One-Step-Printed, Highly Sensitive, Textile-Based, Tunable Performance Strain Sensors for Human Motion Detection. Adv. Mater. Technol. 2020, 5, 1990925. [CrossRef]

35. Stanford, M.G.; Li, J.T.; Chen, Y.; McHugh, E.A.; Liopo, A.; Xiao, H.; Tour, J.M. Self-Sterilizing Laser-Induced Graphene Bacterial Air Filter. Am. Chem. Soc. Nano 2019, 13, 11912-11920. [CrossRef]

36. Stanford, M.G.; Yang, K.; Chyan, Y.Y.; Kittrell, C.; Tour, J.M. Laser-Induced Graphene for Flexible and Embeddable Gas Sensors. Am. Chem. Soc. Nano 2019, 13, 3474-3482. [CrossRef]

37. Bobinger, M.R.; Romero, F.J.; Salinas-Castillo, A.; Becherer, M.; Luglli, P.; Morales, D.P.; Rodriguez, N.; Rivadeneyra, A. Flexible and robust laser-induced graphene heaters photothermally scribed on bare polyimide substrates. Carbon 2019, 144, 116-126. [CrossRef]

38. Chen, J.; Wang, Y.; Liu, F.; Luo, S. Laser-Induced Graphene Paper Heaters with Multimodally Patternable Electrothermal Performance for Low-Energy Manufacturing of Composites. Am. Chem. Soc. Appl. Mater. Interfaces 2020, 12, $23284-23297$. [CrossRef]

39. Carvalho, A.F.; Fernandes, A.J.S.; Leitao, C.; Deurmeier, J.; Marques, A.C.; Martins, R.; Fortunao, E.; Costa, F.M. Laser-Induced Graphene Strain Sensors Produced by Ultraviolet Irradiation of Polyimide. Adv. Funct. Mater. 2018, 28, 1805271. [CrossRef]

40. Li, R.; Li, C.; He, S.; Di, M.; Yang, D. Radiation effect of keV protons on optical properties of aluminized Kapton film. Radiat. Phys. Chem. 2007, 76, 1200-1204. [CrossRef]

41. Frisoli, J.K.; Hefetz, Y.; Deutsch, T.F. Time-resolved UV absorption of polyimide. Appl. Phys. B 1991, 52, 168-172. [CrossRef]

42. Ponnamma, D.; Vijayan, P.P.; Al-Maadeed, M.A. 3D architectures of titania nanotubes and graphene with efficient nanosynergy for supercapacitors. Mater. Des. 2017, 117, 203-212. [CrossRef]

43. Wang, L.; Wang, Z.; Bakhtiyari, A.; Zheng, H. A Comparative Study of Laser-Induced Graphene by $\mathrm{CO}_{2}$ Infrared Laser and 355 nm Ultraviolet (UV) Laser. Micromachines 2020, 11, 1094. [CrossRef]

44. Vashisth, A.; Kowalik, M.; Gerringer, J.C.; Ashraf, C.; van Duin, A.C.T.; Green, M.J. ReaxFF Simulations of Laser-Induced Graphene (LIG) Formation for Multifunctional Polymer Nanocomposites. Am. Chem. Soc. Appl. Nano Mater. 2020, 3, 1881-1890. [CrossRef] 
45. Oh, J.Y.; Park, D.S.; Shin, B.S. Surface delamination of polyimide using 355-nm nanosecond pulse laser. Appl. Phys. B 2013, 113, 411-415. [CrossRef]

46. Malard, L.M.; Pimenta, M.A.; Dresselhaus, G.; Dresselhaus, M.S. Raman spectroscopy in graphene. Phys. Rep. 2009, 473, 51-87. [CrossRef]

47. Marlen, A.; Buijmsters, J.G.; Pardanaud, C. A Guide to and Review of the Use of Multiwavelength Raman Spectroscopy for Characterizing Defective Aromatic Carbon Solids: From Graphene to Amorphous Carbons. Coatings 2017, 7, 153. [CrossRef]

48. Rathinam, K.; Singh, S.P.; Li, Y.; Kasher, R.; Tour, J.M.; Arnusch, C.J. Polyimide derived laser-induced graphene as adsorbent for cationic and anionic dyes. Carbon 2017, 124, 515-524. [CrossRef]

49. Gurzęda, B.; Buchwald, T.; Nocuń, M.; Bakowicz, A.; Krawczyk, P. Graphene material preparation through thermal treatment of graphite oxide electrochemically synthesized in aqueous sulfuric acid. RSC Adv. 2017, 7, 19904-19911. [CrossRef]

50. Jiao, X.; Qiu, Y.; Zhang, L.; Zhang, X. Comparison of the characteristic properties of reduced graphene oxides synthesized from natural graphites with different graphitization degrees. RSC Adv. 2017, 7, 52337-52344. [CrossRef]

51. Johra, F.T.; Jung, W.G. Hydrothermally reduced graphene oxide as a supercapacitor. Appl. Surf. Sci. 2015, 357, 1911-1914. [CrossRef]

52. Gong, Y.; Li, D.; Fu, Q.; Pan, C. Influence of graphene microstructures on electrochemical performance for supercapacitors. Prog. Nat. Sci. Mater. Int. 2015, 25, 379-385. [CrossRef]

53. Jeong, S.-Y.; Lee, C.-W.; Lee, J.-U.; Ma, Y.-W.; Shin, B.-S. Laser-Induced Biochar Formation through 355 nm Pulsed Laser Irradiation of Wood, and Application to Eco-Friendly pH Sensors. Nanomaterials 2020, 10, 1904. [CrossRef] [PubMed]

54. Kou, L.; He, H.; Gao, C. Click chemistry approach to functionalize two-dimensional macromolecules of graphene oxide nanosheets. Nano-Micro Lett. 2010, 2, 177-183. [CrossRef]

55. Wan, Y.J.; Tang, L.C.; Yan, D.; Zhao, L.; Li, Y.B.; Wu, L.B.; Jiang, J.X.; Lai, G.Q. Improved dispersion and interface in the graphene/epoxy composites via a facile surfactant-assisted process. Compos. Sci. Technol. 2013, 82, 60-68. [CrossRef]

56. Lin, T.; Yingying, L.; Lulu, Y.; Peng, C. A highly hydrophilic benzenesulfonic-grafted graphene oxide-based hybrid membrane for ethanol dehydration. RSC Adv. 2020, 10, 20358-20367.

57. Chartarrayawadee, W.; Moulton, S.E.; Too, C.O.; Wallace, G.G. Fabrication of graphene electrodes by electrophoretic deposition and their synergistic effects with PEDOT and platinum. Chiang Mai J. Sci. 2013, 40, 750-762.

58. Bourdo, S.E.; Al Faouri, R.; Sleezer, R.; Nima, Z.A.; Lafont, A.; Chhetri, B.P.; Benamara, M.; Martin, B.; Salamo, G.J.; Biris, A.S. Physicochemical characteristics of pristine and functionalized graphene. J. Appl. Toxicol. 2017, 37, 1288-1296. [CrossRef]

59. Lee, J.U.; Ma, Y.W.; Jeong, S.Y.; Shin, B.S. Fabrication of UV Laser-Induced Porous Graphene Patterns with Nanospheres and Their Optical and Electrical Characteristics. Materials 2020, 13, 3930. [CrossRef] [PubMed]

60. Moon, D.I.; Plechkaityte, G.; Choi, T.; Seol, M.L.; Kim, B.; Lee, D.; Han, J.W.; Meyyappan, M. On-Demand Printing of Wearable Thermotherapy Pad. Adv. Healthc. Mater. 2020, 9, 1901575. [CrossRef]

61. Chang, H.; Jia, Y.; Xiao, L.; Chen, H.; Zhao, K.; Chen, Y.; Ma, Y. Three dimensional cross-linked and flexible graphene composite paper with ultrafast electrothermal response at ultra-low voltage. Carbon 2019, 154, 150-155. [CrossRef]

62. Feng, J.; Guo, Z. Wettability of graphene: From influencing factors and reversible conversions to potential applications. Nanoscale Horiz. 2019, 4, 339-364. [CrossRef] [PubMed] 